Conclusions Migration is a contemporary global issue that can exacerbate child vulnerability to maltreatment. There is a need to tackle issues of diversity head on in order to protect children adequately. Lessons from recent cases have not been learned and whilst potentially uncomfortable, pragmatic guidance is required.

\section{POLICY ACTION TO PROMOTE THE DEVELOPMENT OF CHILD MALTREATMENT PREVENTION ACTION PLANS IN EUROPE}

Dinesh Sethi, Vittoria Crispino. WHO Regional Office for Europe, Copenhagen, Denmark

\subsection{6/injuryprev-2016-042156.441}

Background Child maltreatment is common in globally and in the European Region. In the European facts and the Global status report on violence prevention, $78 \%$ of the countries participating reported that they had developed action plans to prevent child maltreatment. Investing in Children: the European Child Maltreatment Prevention Action Plan 2015-2020 adopted by Member States has an aspirational target to reduce child maltreatment by $20 \%$ by 2020 . To determine whether these plans are likely to result in programme implementation, a content analysis was undertaken.

Methods National data coordinators from the 41 countries in the WHO European Region that took part in the global survey were contacted to request copies of national action plans (NAPs). Internet searches were also conducted on the official government web sites. On this basis, 35 NAPs were identified, of which four were sub-national. A content analysis was conducted using an established methodological framework (Schopper et al).

Results Almost all NAPs (97\%) described multisectoral engagement. Whereas all NAPs had clearly stated objectives, in only one was there a quantified target. All NAPs had achieved government approval; however only $43 \%$ had a clearly stated budget for implementation and $66 \%$ had a clearly stated lead agency for coordinating the actions of the different actors. Whereas $94 \%$ had clearly outlined interventions and activities aimed at achieving the corresponding objectives, all focused on child protection interventions (such as detection, helplines), and fewer had an emaphsis on primary prevention activities such as home vsiitng and prenting support. Countries with NAPs were more likely to have primary prevention interventions than those without.

Conclusions This analysis shows that progress is being made in developing action plans for child maltreatment prevention, but inadequate attention is being given to preventive interventions and most of the focus is on child protection. Governance mechanisms need to be strengthened to ensure more concerted national actions. It is proposed that one way forward would be the development of more NAPs with a clearly defined lead agency, budget and quantified targets. These findings will be discussed in the light of policy success stores from other areas such as road safety.

\section{Safe Communities, Suicide and Self-harm Prevention}

\author{
Post Mon 1.6
}

\section{COLLECTING PERCEPTIONS: REACHING THE HARD TO REACH}

Helena Bishop, David Lane. Cardinia Shire Council, Australia

10.1136/injuryprev-2016-042156.442

Background Research and statistics on safety and injury in Australia are readily available as they are routinely collected and collated by government authorities, academics and other professionals; however obtaining local perception data proves more challenging. Perception data paints a vital picture of safety in a community, as people's perceptions drive their actions. Cardinia Shire Council is working towards designation as an International Safe Community, and understanding community perceptions is critical in establishing the strategic direction to improving safety and reducing injury.

Methods A comprehensive consultation process was created, focussing on inclusion of the most commonly hard to reach groups such as kindergarten children, non-English speaking residents, gay, lesbian and transgender people, disengaged youth and farmers. Deviating from traditional consultation methods, a range of creative activities were developed including youth debates, storytelling and colouring-in, photo-language, visual art sessions and world cafes, each aimed at increasing participation and generating deeper thoughts and feelings.

Results By altering normal processes, and providing creative alternative methods aimed at the most hard to reach, a far greater number of the population were engaged, representative of the full diversity within the community. Information gathered was then used in conjunction with existing research and data to develop a set of priority areas which will help to create a safer community.

Conclusions Standard consultation activities aren't always suitable for every occasion. Hard to reach groups within the community need a fresh and creative approach in order to add value to any community engagement process. Local Government must place value on genuine consultation with all sectors of the community, and be open to adjusting normal consultation processes.

\section{EXPANSION FROM ONE TO THREE: THE AUSTRIAN SAFE CHILDREN COMMUNITY GROWS}

Sabine Distl, Peter Spitzer, Gudula Brandmayr. Safe Kids Austria/Grosse Schuetzen Kleine, Austria

10.1136/injuryprev-2016-042156.443 
Background The Safe Children Community Deutschlandsberg was expanded to the Safe Children Community of Southwest Styria which now comprises three districts. Initiation, development and implementation of successful projects and programs have furthered the reduction of child injury rates. Additionally, evaluation of programs, measures, and injury data was carried out to determine whether the efforts achieved the desired results.

Methods The steering committees of each district comprising all relevant representatives established working groups for categories such as safety in traffic, at home, in school and preschool, during sports, and during leisure time, as well as injury surveillance. A variety of child-safety activities in different settings were developed, involving as many organisations, institutions, schools and professional groups as possible, as well as local media.

Results Data surveillance demonstrated a reduction in child injuries. The relative injury rate of the Safe Children region decreased from 216/1000 in 2012 to 201/1000 in 2014. The pilot district Deutschlandsberg (designated in 2011 as the first Safe Children Community) was able to reduce the child injury rate from 195 in 2012 to 180 in 2014.

Conclusions Motivating a community to carry out injury-prevention initiatives is much easier when the focus is on children. It is also very useful to have champions from all public and private sectors and areas on the steering committees and in the working groups. In addition, it is helpful if a structure of participation is supported by the top-down-principle in the public sector. Despite all the internal motivation, a Safe Children Community has to be driven by external input and expertise. In order to develop and realise projects and receive the attention of Safe Kids Austria as a coordinating body, it is important to have the financial support of the Styrian Government and the districts themselves.

\section{KENTUCKY SAFE COMMUNITIES: A MODEL FOR RECRUITMENT AND GROWTH, 2012-2017}

${ }^{1}$ Genia McKee, ${ }^{2}$ Carrie Nie. ${ }^{1}$ University of Kentucky, Kentucky, USA; ${ }^{2}$ National Safety Council, Safe Communities America, USA

\subsection{6/injuryprev-2016-042156.444}

Background After several years of decreasing injury rates, in 2010, there began an upward injury fatality trend in Kentucky fueled largely by increases in accidental drug overdose and suicide. In 2012, Kentucky's age-adjusted injury fatality rate had increased from 76.1 in 2010 to 81.8 per 100,000 population.

Description of the problem The state has 120 counties and a total population of 4.4 million. Numerous agencies are charged with injury prevention, however there is a lack of coordination and local injury data, making prevention efforts fragmented and inefficient. We adopted the Safe Communities model as a way to address rising injury rates. The Safe Community model originated with the World Health Organisation's Collaborating Centre on Community Safety Promotion's Karolinska Institute.

Results In 2012, the Kentucky Injury Prevention and Resource Centre (KIPRC), Kentucky's lead injury prevention agency, became a Safe Community Affiliate Support Centre and entered into a partnership with the National Safety Council (NSC) and Safe Communities America with the following five year goals: (1) half the population of the state living within a Safe Community, (2) assist with local prevention planning and, (3) develop local data reports. As of July 2015, there are 8 communities certified or in process, holding nearly $40 \%$ of the state's population, and injury data reports are available for all counties.
Conclusions The Safe Communities approach has been shown to be effective in saving lives and reducing costs. A recent NSC study showed that after 10 years of rising injuries and injury rates in one community, the decision to seek Safe Community accreditation was followed by a 2 -year decline in injury hospitalizations. In those two years, the study showed that nearly 300 hospitalizations may have been prevented, saving the community over $\$ 14$ million in health care costs.

\section{5 "STRENGTHENING HEALTH SAVING"}

1,2Leonor Leinecker, ${ }^{1}$ Nadia Rivera Leinecker, ${ }^{1}$ Ricardo Slavusky, ${ }^{2}$ Augusto Ittig, ${ }^{2}$ Laura Flores. ${ }^{1}$ University Nacional De Jujuy, Jujuy, Argentina; ${ }^{2}$ Secretaria Community Protection, Ministry of Government of Jujuy, Jujuy, Argentina

\subsection{6/injuryprev-2016-042156.445}

Background The province of Jujuy is located in a seismic zone with increasing activity. It is essential that your people know how to act in emergencies and know first-aid; key then is to teach and strengthen the community first responders.

Methods courses of theoretical and practical training in medical first aid are made: for university students and representatives of NGOs to increase the number of "Health Lifeguards: trained to train" that expand the coverage and call this training to all the population of the Province of Jujuy. Courses are taught from the race for Health Educator, Faculty of humanities and social sciences. They have zero cost to those who perform and is planned for 1200 graduation trainers, which will allow the creation of 240 training teams for training gives coverage to the whole province of Jujuy. The political-economic framework is guaranteed by agreements concluded between the National University of Jujuy and the Secretariat of the Community Protection of the Ministry of Government of the Province of Jujuy .

Results In 2014 certified 235 university students and NGO representatives as "Lifeguard Health trained to train" in 2015 training is extended to members of social and sporting institutions, neighbourhood and social organisations and members of non-formal education, with 456 students for certified "Lifeguard Health: trained to train" strengthening Courses are conducted in "First responder" to police, firefighters and civil protection and first responders, granting 95 certifications.

Conclusions The general population and in particular the first respondent properly trained how to act in an emergency, helps reduce fatal consequences and the consequences of the same, reducing YPLL injuries and disabilities.

\section{HEALTHY NIGHTLIFE: ELIMINATE RISK, PROMOTE PROTECTIVE FACTORS \& CITY RESILIENCE (COIMBRA, PORTUGAL)}

${ }^{1}$ João Redondo, ${ }^{2}$ Fernando Mendes, ${ }^{3}$ Isabel Fonseca, ${ }^{4}$ Jorge Alves, ${ }^{5}$ Paulo Anjos, ${ }^{6}$ Irma Brito, ${ }^{7}$ Henrique Armindo, ${ }^{8}$ António Monteiro, ${ }^{9}$ Laura Diogo, ${ }^{10}$ Cristina Baptista, ${ }^{1}$ Paulo Simões, ${ }^{1}$ Filipa Sola, ${ }^{1}$ Alexandre Fernandes. ${ }^{1}$ Centre for Prevention and Treatment of Psychological Trauma (CPTTP), Department of Psychiatry, Coimbra University Hospital Centre, CHUC, Portugal; ' ${ }^{2}$ European Institute of Studies on Prevention (IREFREA, Portugal); ${ }^{3}$ Emergency Department, CHUC, Portugal; ${ }^{4}$ Municipality of Coimbra, Portugal; ${ }^{5}$ Associação Existências, Portugal; ${ }^{6}$ Higher School of Nursing, Coimbra, Portugal; ${ }^{7}$ National Guard (GNR), Coimbra, Portugal; ${ }^{8}$ Public Security Police (PSP) of Coimbra, Portugal; ${ }^{9}$ Coimbra Group of Schools West, Portugal; ${ }^{10}$ Coimbra Group of Schools Central, Portugal

10.1136/injuryprev-2016-042156.446 